\title{
Exploration of long noncoding RNA in bovine milk exosomes and their stability during digestion in vitro
}

\author{
Bin Zeng, ${ }^{*}$ Ting Chen, ${ }^{*}$ Mei-Ying Xie, Jun-Yi Luo, Jia-Jian He, Qian-Yun Xi, Jia-Jie Sun, $†$ \\ and Yong-Liang Zhangt \\ Guangdong Provincial Key Laboratory of Animal Nutrition Control, National Engineering Research Center for Breeding Swine Industry, \\ College of Animal Science, South China Agricultural University, Guangzhou, 510642, China
}

\begin{abstract}
Previous studies have demonstrated that bovine milk contains mRNA and microRNA that are largely encapsulated in milk-derived exosomes. However, little information is available about long noncoding RNAs (lncRNA) in bovine milk. Increasing evidence suggests that lncRNA are of particular interest given their key role in gene expression and development. We performed a comprehensive analysis of lncRNA in bovine milk exosomes by RNA sequencing. We used a validated human in vitro digestion model to investigate the stability of lncRNA encapsulated in bovine milk exosomes during the digestion process. We identified 3,475 novel lncRNA and 6 annotated lncRNA. The lncRNA shared characteristics with those of other mammals in terms of length, exon number, and open reading frames. However, lncRNA showed higher expression than mRNAs. We selected 12 lncRNA of high-expression abundance and identified them by PCR. Gene ontology (GO) enrichment and Kyoto Encyclopedia of Genes and Genomes (KEGG) pathway analyses showed that lncRNA regulate immune function, osteoblastogenesis, neurodevelopment, reproduction, cell proliferation, and cell-cell communication. We also investigated the 12 lncRNA using quantitative real-time PCR to reveal their expression profiles in milk exosomes during different stages of lactation (colostrum $2 \mathrm{~d}, 30 \mathrm{~d}, 150 \mathrm{~d}$, and 270 d); their resulting expression levels in milk exosomes showed variations across the stages. A digestion experiment showed that bovine milk exosome lncRNA was resistant to in vitro digestion with different digestive juices, including saliva, gastric juice, pancreatic juice, and bile juice. Taken together, these results show for the first time that cow milk contains lncRNA, and that
\end{abstract}

\footnotetext{
Received January 6, 2019.

Accepted April 1, 2019.

*These authors contributed equally to this work.

$\dagger$ †Corresponding authors: jiajiesun@scau.edu.cn and zhangyl@scau
} .edu.cn their abundance varied at different stages of lactation. As expected, bovine milk exosomal lncRNA were stable during in vitro digestion. These findings provide a basis for further understanding of the physiological role of milk lncRNA.

Key words: bovine, milk exosomes, long noncoding RNA, stability

\section{INTRODUCTION}

Milk has been identified as a rich source of vital nutrients contributing to health (Admyre et al., 2007). It contains a diverse mixture of components, including nutrients, milk fat globules, growth factors, immune cells, antibodies, cytokines, and antimicrobial peptides that play a pivotal role in infant development (Savino and Liguori, 2008; Dieterich et al., 2013). The beneficial effects of milk include decreased risk of sudden infant death syndrome, reduced risk of neonatal infection, and more optimal metabolic development throughout childhood (Hauck et al., 2011). Bovine milk is widely used as a dairy product, especially in infant formula, and it is an important material in the food industry.

Recently, increasing attention has been given to milkderived exosomes, which are small, lipid-bilayer membrane vesicles. Exosome cargos include proteins, lipids, DNA, and various RNA species. Emerging evidence has shown that exosomal RNA participate in many regulated pathways, including cellular growth, antiviral activity, and insulin sensitivity (Vlassov et al., 2012; Nabet et al., 2017; Ying et al., 2017). Milk-derived exosomes have been found in humans, cows, pigs, and rats (Chen et al., 2014; Izumi et al., 2015; Hock et al., 2017), and are involved in multiple biological processes. Previous studies have reported that bovine milk contains microRNAs (miRNA; Chen et al., 2010) and mRNAs (Izumi et al., 2015). As well, expression levels of exosomal miRNA were different between bovine colostrum and mature milk. Bovine milk exosomes (BME) contain more immune-related miRNA in colostrum than in mature milk (Izumi et al., 2012; Sun et al., 2013b). Long noncoding RNA (lncRNA) are those longer than 200 nucleotides. 
They have received much attention in the past several years, and have been found to play important functional roles in almost all biological processes, including transcriptional regulation, epigenetic gene regulation, and disease (Batista and Chang, 2013; Karlsson et al., 2016). For example, exosome-transmitted lncRNA PTENP1 suppresses bladder cancer progression in vitro and in vivo (Zheng et al., 2018). However, few reports are available on bovine milk lncRNA and their profiles in different lactation periods.

The literature has clearly indicated that milk exosomal RNA can be taken up by human macrophages and intestinal cells (Izumi et al., 2015; Wolf et al., 2015) and are permeable to the intestinal barrier in vitro (Rani et al., 2017). Indeed, BME and their RNA cargos in the tissues of mice (Manca et al., 2018) are bioactive in attenuating arthritis (Arntz et al., 2015) and regulating skeletal muscle growth and development (Mobley et al., 2017; Leiferman et al., 2018). However, it is a harsh journey for breast milk RNA to play a role in infant development and maturation (Tomé-Carneiro et al., 2018), and whether exosomal RNA can resist digestive processes remains controversial (Title et al., 2015).

In this study, we confirmed that lncRNA were present in BME. We also identified the abundance of 12 lncRNA at different periods of lactation using quantitative real-time PCR analyses. We also examined the resistance of BME lncRNA to different digestive processes in vitro. Our findings may provide a better understanding of bovine milk in terms of molecular events and physiological functions.

\section{MATERIALS AND METHODS}

\section{Milk Sample Preparation and Milk Exosome Isolation}

Milk samples that conformed to Chinese national quality standards were collected from FengXing farm in southern China (Guangdong). Milk from 8 healthy Holstein cows (50 to $100 \mathrm{~d}$ in lactation ) was mixed in equal amounts to construct a pooled milk sample. We used the pooled milk sample for lncRNA sequencing and in vitro digestion. milk samples in 4 different lactation periods were collected from 24 healthy Holstein cows at $2 \mathrm{~d}$ (colostrum, 6 cows), $30 \mathrm{~d}$ (6 cows), 150 d (6 cows), and $270 \mathrm{~d}$ (6 cows) postpartum. All milk samples were frozen immediately and kept at $-30^{\circ} \mathrm{C}$ until use. Milk exosomes were separated as previously described (Zhou et al., 2012). Briefly, raw bovine milk samples $(40 \mathrm{~mL})$ were subjected to 2 successive centrifugations at 2,000 and $12,000 \times g$ at $4^{\circ} \mathrm{C}$ for $30 \mathrm{~min}$ to remove milk fat globules and cellular debris. The resulting supernatant was filtered through a $0.45-\mu \mathrm{m}$ filter to obtain a clear whey fraction. Then, the clear whey fraction was prepared for ultracentrifugation at $160,000 \times g$ for $2 \mathrm{~h}$ by an SW70Ti rotor (Optima XPN100; Beckman Coulter Instruments, Fullerton, CA), and the pellets were resuspended in $2 \mathrm{~mL}$ of PBS and passed through a $0.22-\mu \mathrm{m}$ filter to obtain exosome solutions. The exosome solutions were stored at $-80^{\circ} \mathrm{C}$ for further analysis.

\section{RNA Extraction and IncRNA Sequencing}

We extracted total RNA from BME samples using Trizol reagent (Invitrogen, Carlsbad, CA) according to the manufacturer's protocol. Total RNA was used as input material for the construction of a cDNA library. The sample was prepared as previously described (Ma et al., 2017). The library was constructed using a NEBNext Ultra Directional RNA Library Prep Kit for Illumina (New England Biolabs Inc., Ipswich, MA) after the removal of ribosomal RNA using an Epicenter Ribo-zero rRNA Removal Kit (Epicenter, Madison, WI). Library sequencing was performed on an Illumina HiSeq 4000 platform (Illumina Inc., San Diego, CA) and 150-bp paired-end reads were generated at the Novogene Bioinformatics Institute (Beijing, China).

\section{Sequence Data Analysis}

First, we processed raw reads in fastq format through in-house perl scripts. Then, we obtained clean reads by removing low-quality reads and those containing adapters and poly- $\mathrm{N}$ from the raw data. At the same time, Q20, Q30, and GC content of the clean data were calculated. The Q20 and Q30 content represent the percentage of bases with Phred value greater than 20 and 30 in the total bases, respectively. All of the subsequent analyses were performed using high-quality data (mapped reads). An index of the reference genome was built using bowtie 2 v2.2.8 and paired-end clean reads were aligned to the reference genome using HISAT2 v2.0.4 (Langmead and Salzberg, 2012). The mapped reads were assembled by StringTie (v1.3.1) software in a reference-based approach (Pertea et al., 2016).

We used 3 types of coding potential analysis software, CNCI (v2; Sun et al., 2013a), CPC (0.9-r2; Kong et al., 2007), and Pfam-scan (v1.3; Bateman et al., 2004), to distinguish mRNA from lncRNA. The intersecting results of each software were defined, and those that were determined to be noncoding were designated as candidate lncRNA. We used Cufflink (v2.1.1) to calculate fragments per kilobase million (FPKM) for both lncRNA and coding genes (Trapnell et al., 2010). The transcript expression levels (FPKM value) were expressed as fragments per kilobase of transcript per 
million mapped reads values. Target genes located in cis to lncRNA were predicted, based on the assumption that lncRNAs regulate their neighboring regions. Coding genes $100 \mathrm{~kb}$ upstream and downstream of all lncRNAs were searched, and their functional roles were analyzed. We implemented gene ontology (GO) enrichment analysis of lncRNA target genes using the GOseq $\mathrm{R}$ package (Young et al., 2010), in which gene length bias was corrected; GO terms with a corrected $P$-value of $<0.05$ were considered significantly enriched. In the identified Kyoto Encyclopedia of Genes and Genomes (KEGG) pathways, we conducted statistical enrichment of target genes using KOBAS software (Mao et al., 2005).

\section{LncRNA Identification by PCR}

Total RNA from bovine milk exosome samples was extracted using Trizol reagent (Invitrogen) according to the manufacturer's protocol and cDNA was synthesized using a reverse transcription kit (PrimeScript RT Reagent Kit with gDNA Eraser; TaKaRa, Dalian, China) using $500 \mathrm{ng}$ of total RNA according to the manufacturer's instructions (https://www.takarabio .com/search-results?term=RR047A). The PCR was performed on C1000 Touch Thermal Cycler (Bio-Rad, Hercules, CA) in a final $20-\mu \mathrm{L}$ volume reaction containing $2 \mu \mathrm{L}$ of cDNA, $7 \mu \mathrm{L}$ of nuclease-free water, $1 \mathrm{mM}$ each primer and $10 \mu \mathrm{L}$ of $2 \times$ Tap Master Mix (Vazyme, Nanjing, China). The PCR program was as follows: 5 min at $95^{\circ} \mathrm{C}, 35$ cycles of $30 \mathrm{~s}$ at $95^{\circ} \mathrm{C}, 30 \mathrm{~s}$ at the cor- responding annealing temperature and $72^{\circ} \mathrm{C}$ for $30 \mathrm{~s}$, followed by $72^{\circ} \mathrm{C}$ for $10 \mathrm{~min}$. The primers were designed using Primer 5.0 (Supplemental Table S1; https://doi .org/10.3168/jds.2019-16257). We confirmed the PCR products of 12 lncRNA by agarose gel and sequencing.

\section{Digestion In Vitro}

Milk was digested in vitro as described previously (Kopf-Bolanz et al., 2012). All chemicals and enzymes for in vitro digestion were purchased from Sigma-Aldrich (St. Louis, MO). Briefly, using a table concentrator at $37^{\circ} \mathrm{C}, 2.25 \mathrm{~mL}$ of cow milk was initially mixed with 3 $\mathrm{mL}$ of salivary juice and incubated for $5 \mathrm{~min}$; then, 6 $\mathrm{mL}$ of gastric juice was added to incubate for $60 \mathrm{~min}$; finally, $6 \mathrm{~mL}$ of pancreatic juice plus $3 \mathrm{~mL}$ of bile juice were added to incubate for $60 \mathrm{~min}$. As a negative normal saline control (undigested), $2.25 \mathrm{~mL}$ of milk mixed with $18 \mathrm{~mL}$ of normal saline went through the same procedure for in vitro digestion. Whey fraction and exosomes isolation were carried out as in Milk Sample Preparation and Milk Exosome Isolation, above. The digested conditions are shown in Figure 1.

\section{Transmission Electron Microscopy and Particle Size Analysis}

Purified exosomal fractions of $10 \mu \mathrm{L}$ were analyzed by transmission electron microscopy (TEM; JEM2000EX; Jeol, Tokyo, Japan). Samples were placed on formvar-coated copper grids for 2 min, washed briefly

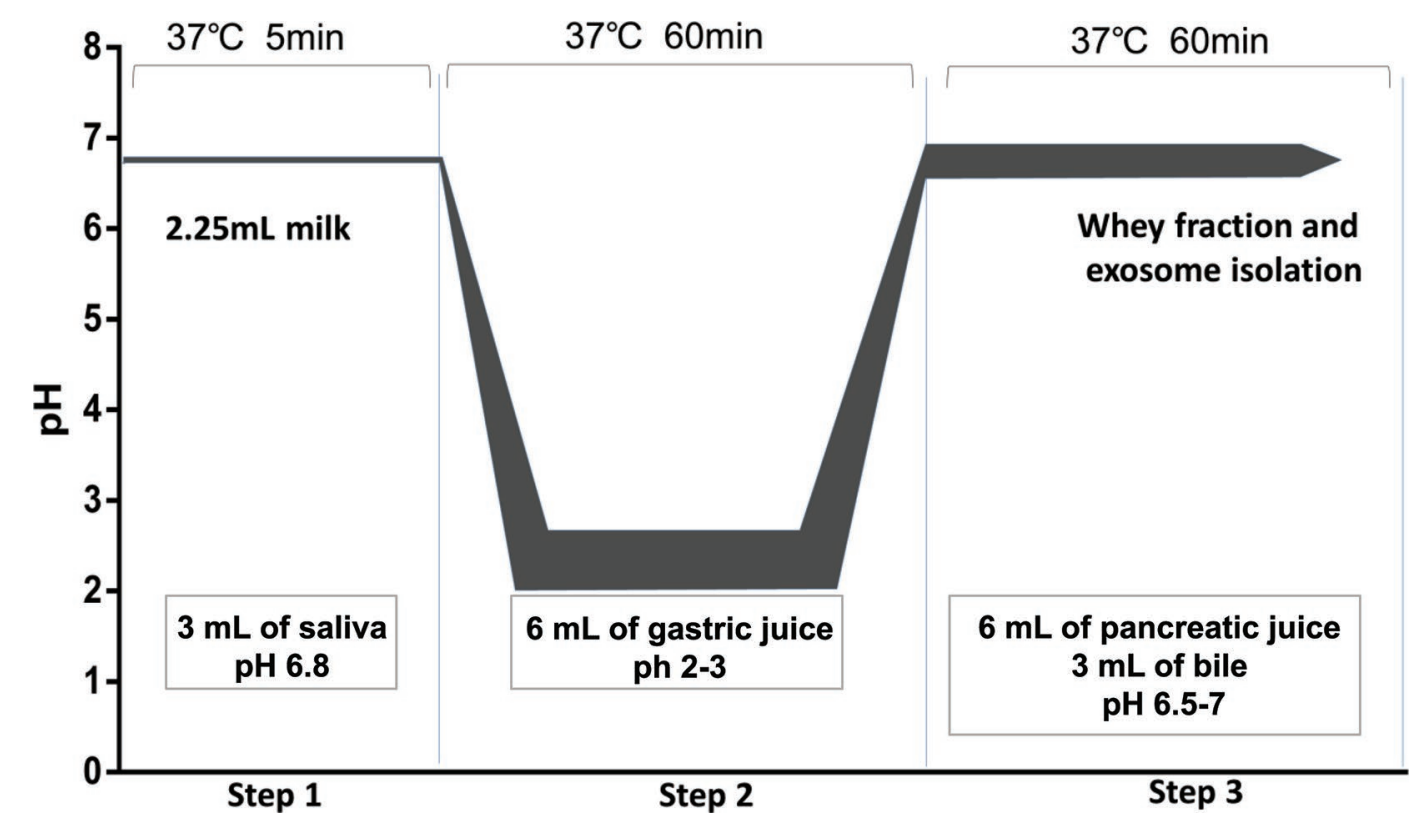

Figure 1. Incubation times and conditions during in vitro digestion of milk. 
in ultrapure water, negatively stained with $1 \%$ uranyl acetate, and observed. Size distribution was determined by the Zetasizer (Malvern Panalytical, Malvern, UK) at $25^{\circ} \mathrm{C}$.

\section{BCA Protein Assay, SDS-PAGE and Western Blot Analyses}

We assayed all protein content using the Pierce BCA Protein Assay Kit (ThermoScientific, Waltham, MA) according to the manufacturer's instructions (https:/ /www.thermofisher.com/order/catalog/product/23225 ?SID=srch-srp-23225), and SDS-PAGE (10\%) was used to separate proteins. Equal amounts of proteins $(20 \mu \mathrm{g})$ from milk whey samples (undigested and in vitro digested) were run on the gel, and stained with 0.1\% Coomassie Brilliant Blue R-250. To confirm exosomes from undigested and in vitro-digested milk, we used 2 positive markers (CD9 and CD63) for Western blots. The proteins were separated by SDS-PAGE and transferred to a polyvinylidene difluoride membrane (Millipore, Billerica, MA). After blocking with 5\% skim milk for $2 \mathrm{~h}$, the membranes were incubated overnight at $4^{\circ} \mathrm{C}$ with specific antibodies against CD9 and CD63 (1:1,000; Sangon Biotech, China). We applied horseradish peroxidase-conjugated goat anti-rabbit $\operatorname{IgG}\left(\mathrm{H}^{+} \mathrm{L}\right.$; 1:50,000; Jackson ImmunoResearch, West Grove, PA) as a secondary antibody for $1 \mathrm{~h}$ at room temperature. The proteins were measured using a FluorChem M Fluorescent Imaging System (ProteinSimple, Santa Clara, CA).

\section{IncRNA Expression Analysis}

We extracted total RNA from exosomes isolated from normal saline control (undigested) milk, in vitrodigested milk, and bovine milk from 4 different periods of lactation using Trizol reagent (Invitrogen) according to the manufacturer's protocol. We synthesized cDNA using a reverse transcription kit (PrimeScript RT Reagent Kit with gDNA Eraser; TaKaRa) using 500 ng of total RNA according to the manufacturer's instructions (https://www.takarabio.com/search-results?term $=$ RR047A). We used SYBR Green qRT-PCR Master Mix reagent (Promega, Madison, WI) sense and antisense primers for real-time quantitative PCR. We performed quantitative real-time PCR analysis using the CFX96 Real-Time PCR Detection System (Bio-Rad). We normalized lncRNA levels in BME against a synthesized exogenous reference $\lambda$ polyA + RNA (TaKaRa; Gilsbach et al., 2006). According to the instructions (https: / / www.takarabio.com/search-results?term = $3789)$, we added synthetic $\lambda$ polyA + RNA $\left(1.8 \times 10^{8}\right.$ copies) to $1.2 \mathrm{~mL}$ of denatured sample (all BME sam- ples with equal protein concentration and equal volume were mixed with Trizol reagent). Next, total RNA was extracted according to the instructions provided with the Trizol reagent. The expression of indicated genes was normalized to exogenous reference control using the $2^{-\Delta \Delta \mathrm{Ct}}$ method.

\section{Statistical Analysis}

Quantitative real-time PCR was performed in triplicate. All data were expressed as means \pm standard error of the mean (SEM). Data were analyzed using SPSS 17.0 (SPSS Inc., Chicago, IL). One-way ANOVA followed by Tukey's multiple comparison was used to compare the lncRNA levels in exosomes isolated from bovine milk in different periods of lactation. We used $t$-tests to compare lncRNA level in exosomes isolated from undigested milk and in vitro-digested milk. We considered $P$-values $<0.05$ to be statistically significant.

\section{RESULTS}

\section{Identification of IncRNA in BME Using RNA-seq}

For RNA-seq data, we obtained $72,899,916$ raw reads and 68,824,548 clean reads after removing lowquality sequences and adaptor sequences. Data output quality and mapped reads information are shown in Supplemental Tables S2 and S3, respectively (https:/ /doi.org/10.3168/jds.2019-16257). Based on structural and noncoding functional characteristics of lncRNA, we identified 3,475 novel lncRNA after filtering out annotation transcripts (Figure 2A-B; detailed information shown in Supplemental Files S1 and S2, https://doi .org/10.3168/jds.2019-16257), including 86.3\% (2,998) long intergenic noncoding RNA, 4.1\% (141) antisense lncRNA, and 9.7\% (336) intronic lncRNA (Figure 2C). We detected 6 annotated lncRNA in BME (http://asia .ensembl.org/index.html), with detailed information shown in Supplemental Files S3 and S4 (https://doi .org/10.3168/jds.2019-16257).

\section{Genomic Features of IncRNA in Bovine Milk Exosomes}

We analyzed gene structures and expression levels for comparison between lncRNA and mRNA. In agreement with a previous study (Trapnell et al., 2010), lncRNA (novel and annotated lncRNA) are shorter than protein-coding transcripts (Figure 2D), and their genes tend to contain fewer exons (Figure 2E). Most of the mRNA had longer open reading frames than lncRNA (Figure $2 \mathrm{~F}$ ), but our findings showed higher expression of lncRNA than mRNA in BME (Figure $2 \mathrm{G}$ ). 


\section{Identification of IncRNA by PCR Analysis}

To verify the sequencing results, we randomly selected 12 lncRNA from the top 20 expression levels in sequencing for PCR amplification. The product sizes of all selected lncRNA were fully matched (Figure 3A). Sequencing of 12 lncRNA amplified products showed that 7 lncRNA were fully matched and 5 had 1 to 3 mismatched nucleotides when compared with RNA sequencing (Supplemental Table S4; https://doi.org/10 $.3168 /$ jds.2019-16257).

\section{GO and KEGG Annotation of IncRNA}

Recent studies have suggested that lncRNA may act in cis and affect the gene expression of their chromo-
A

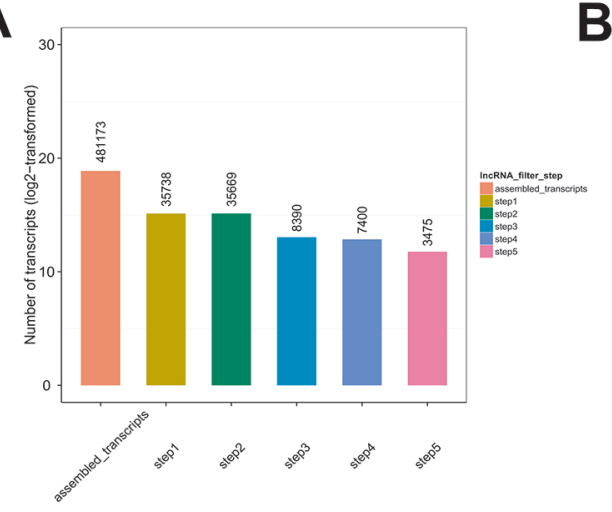

D

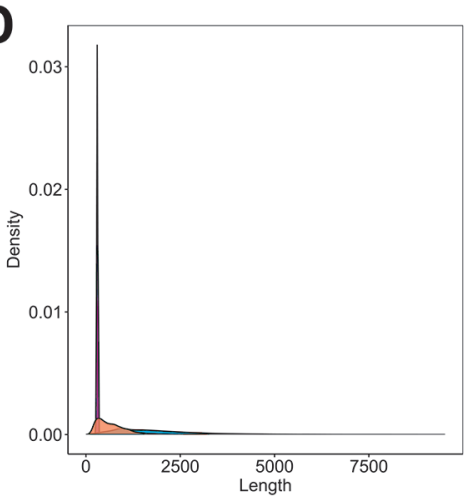

$\mathbf{F}$

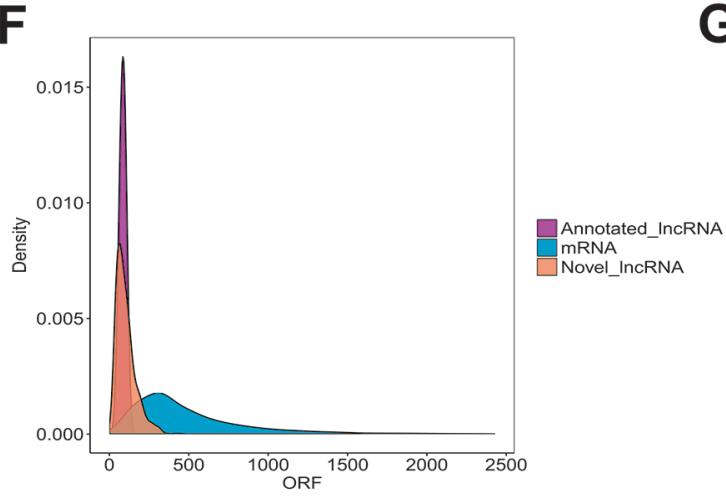

B

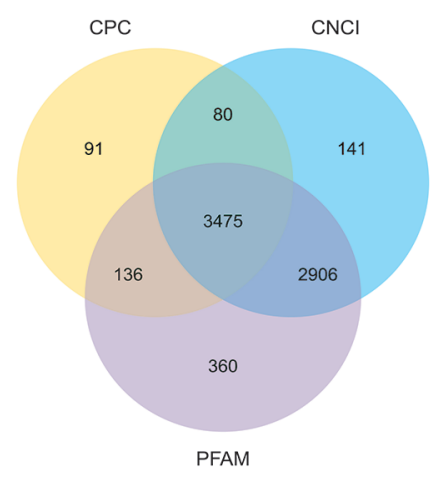

E

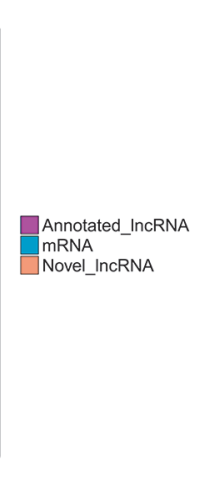

C

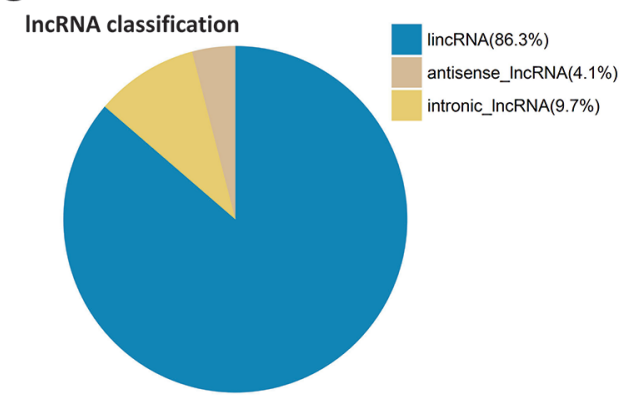

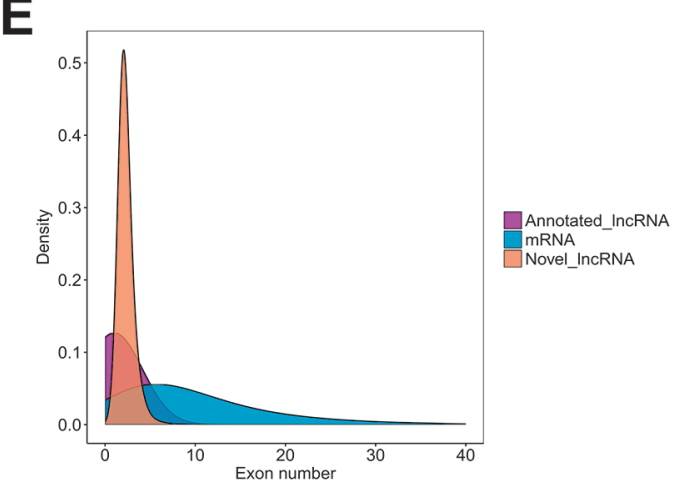

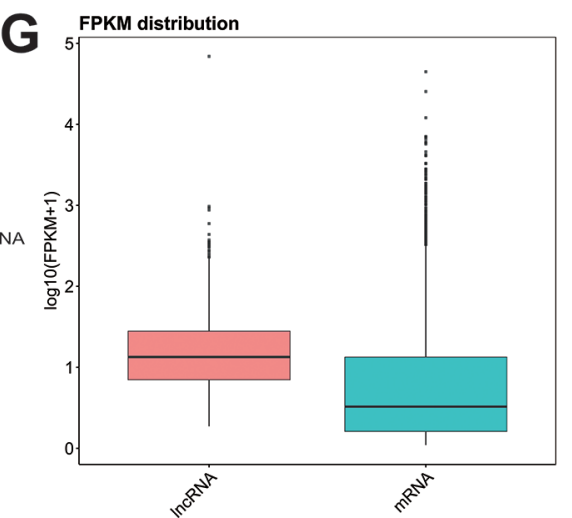

Figure 2. Identification and characterization of long noncoding RNA (lncRNA) in bovine milk exosomes. (A, B) Selection of lncRNA in bovine milk exosomes using CPC, Pfam and CNCI software; 3,475 novel lncRNA were identified after the removal of putative protein-coding

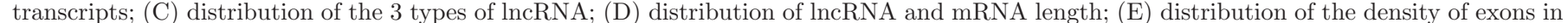

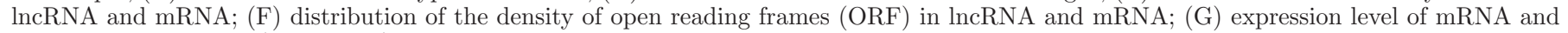

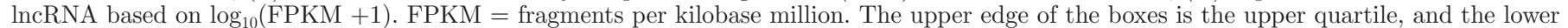

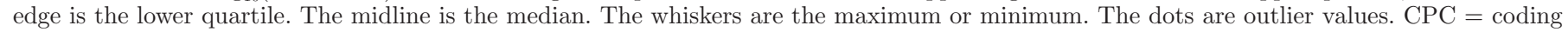
potential calculator; CNCI = coding-noncoding index; PFAM = protein families; ORF = open reading frames. 


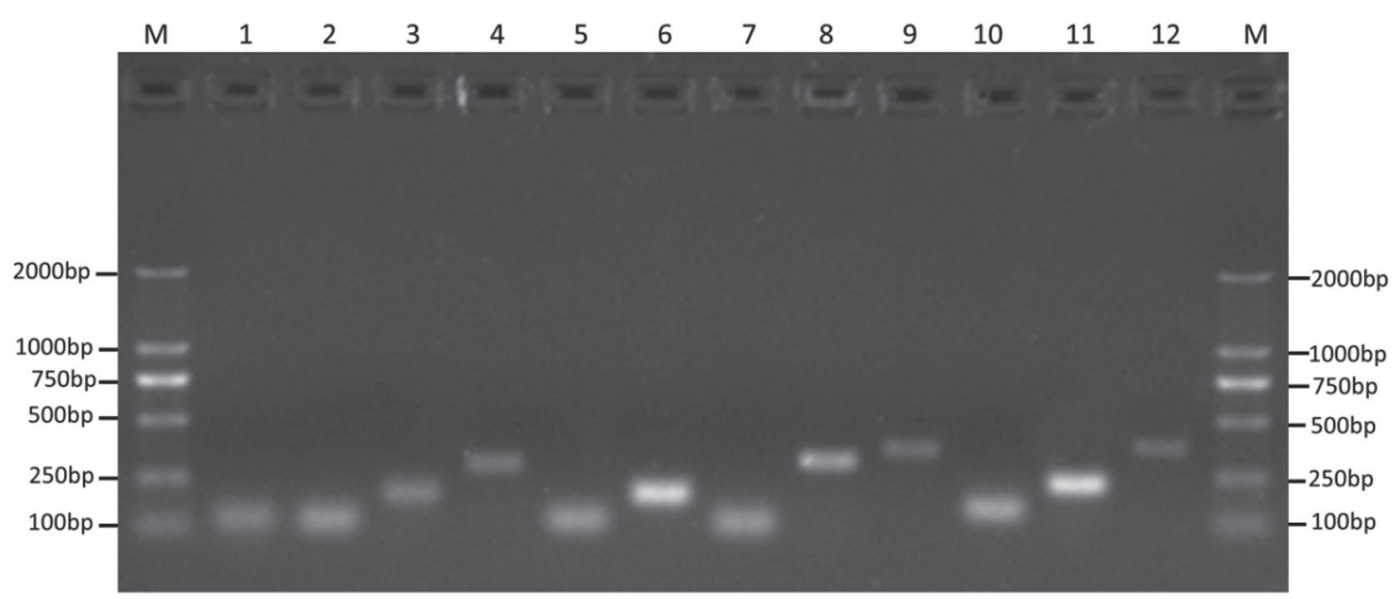

Figure 3. Identification of long noncoding RNA (LNC) PCR product size by agarose gel electrophoresis. Lane M: marker; lanes 1 to 12 , respectively: ENSBTAT00000065829 (119 bp), LNC_001182 (112 bp), LNC_001285 (195 bp), LNC_002259 (298 bp), LNC_001989 (111 bp), LNC_001183 (189 bp), LNC_002066 (101 bp), LNC_002229 (306 bp), LNC_001972 (362 bp), LNC_002303 (144 bp), LNC_001965 (227 bp), LNC_001442 (359 bp).

somal neighborhood, $100 \mathrm{~kb}$ upstream and downstream (Ørom et al., 2010). To investigate the relationship of lncRNA and their neighboring coding genes, we identified BME lncRNA that corresponded to 3,025 protein-coding genes (detailed information shown in Supplemental File S5; https://doi.org/10.3168/jds .2019-16257). Our GO annotation indicated that the predicted target genes were significantly enriched in antigen processing and presentation, positive regulation of type I interferon production, negative regulation of tumor necrosis factor production, thymus development, osteoblast differentiation, embryonic cranial skeleton morphogenesis, neuron projection development, response to progesterone, androgen receptor binding, cell division, cell-cell adhesion, and extracellular exosome terms (Figure 4A). Our KEGG pathway analysis showed that lncRNA target genes were significantly enriched in ribosomes, the neurotrophin signaling pathway, the FceRI signaling pathway, and the gonadotropin-releasing hormone signaling pathway. Regulation of the actin cytoskeleton, vascular endothelial growth factor signaling pathway, intestinal immune network for IgA production, hypoxia-inducible factors-1 signaling pathway and $\mathrm{Fc} \gamma \mathrm{R}$-mediated phagocytosis were also enriched (Figure 4B). These findings suggested that BME lncRNA could regulate fetal growth, development, immune system, and reproduction.

\section{LncRNA Expression in BME in 4 Lactation Periods}

Previous studies have indicated that miRNA demonstrate different expression patterns between colostrum and mature milk. To examine whether lncRNA expression levels are diverse in different lactation periods, we selected 12 high-expressed lncRNA and compared expression levels in 4 periods (d 2 colostrum, d 30, 150, and 270 of lactation) using quantitative real-time PCR. As shown in Figure 5, expression levels of the 12 lncRNA varied during different lactation stages. Expression levels of LNC_001182 and LNC_002303 were higher in colostrum than in mature milk. However, levels of LNC_001442 were higher in the mid- and latelactation periods (150 and $270 \mathrm{~d}$ ) than in colostrum and early lactation $(30 \mathrm{~d})$. Notably, expression of 4 lncRNA (LNC_001965, LNC_001183, LNC_001989, and LNC_002066) was higher in the mid-lactation period $(150 \mathrm{~d})$ than in colostrum and early lactation $(30 \mathrm{~d})$. The expression levels of other selected lncRNA (LNC_001285, LNC_002259, LNC_001972, LNC_002229, and ENSBTAT00000065829) remained unchanged in colostrum and the other 3 lactation periods. These results implied that different expression patterns were present and might be related to their function in milk.

\section{Characterization of Milk Protein, Exosome Stability, and IncRNA Components After In Vitro Digestion}

Milk exosomes were stable, maintaining their characteristic features and lncRNA components in simulated human in vitro digestion. Our SDS-PAGE analysis showed that most of the milk proteins, including abundant casein fractions and $\beta$-lactoglobulin, were digested by the different juices (Figure 6A). We further characterized exosomes isolated from undigested and in vitrodigested milk using transmission electron microscopy and Zetasizer analyses and found that the morphology (Figure $6 \mathrm{~B}$ and $\mathrm{C}$ ) and size (Figure $6 \mathrm{D}$ ) of in vitro- 
digested milk exosomes did not change significantly compared with undigested milk exosomes. Moreover, positive common surface markers CD9 and CD63 were present in both undigested and in vitro-digested milk exosomes (Figure 6E). We used agarose gel to verify the
RNA stability of milk exosomes after in vitro digestion, and results showed that the in vitro digestion process did not change RNA stability (Figure 6F). Quantitative real-time PCR analysis showed that the levels of the 12 lncRNA did not change after in vitro digestion

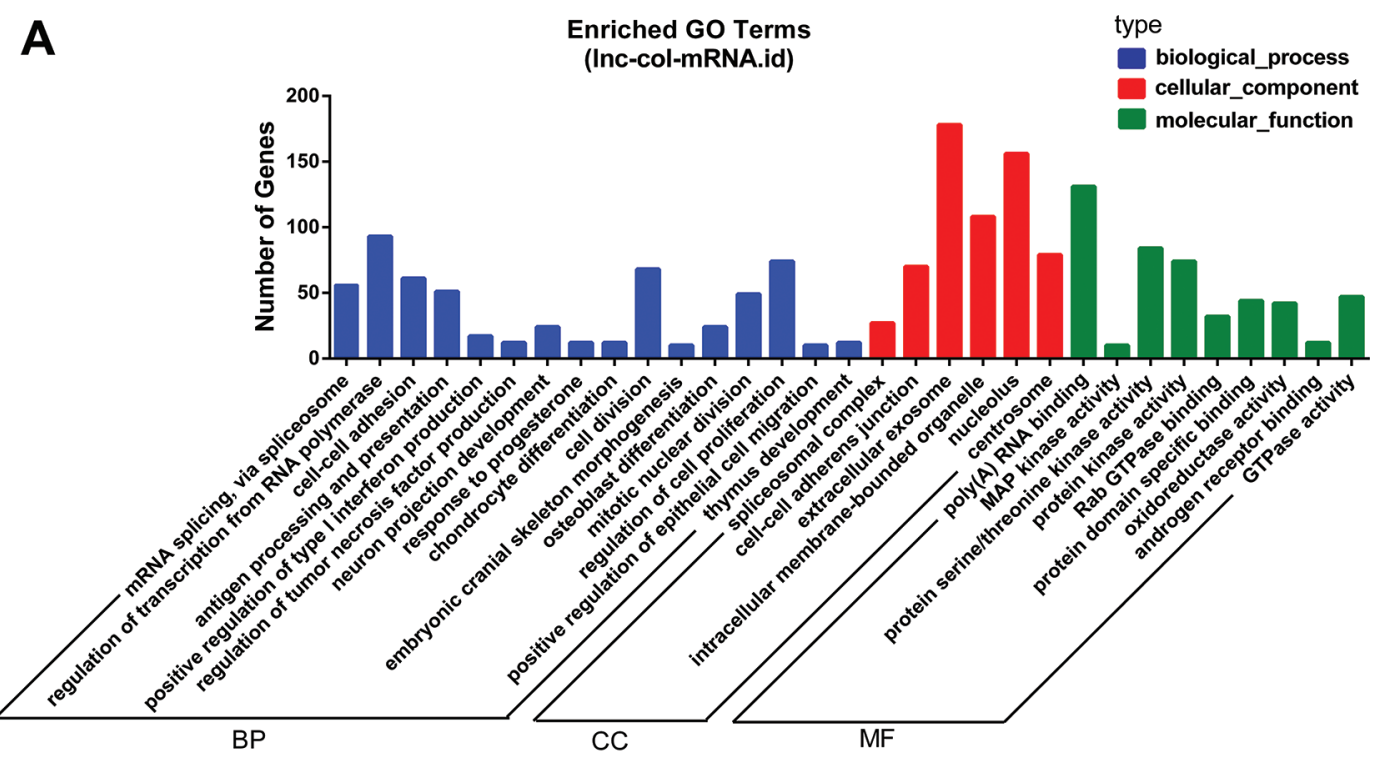

B

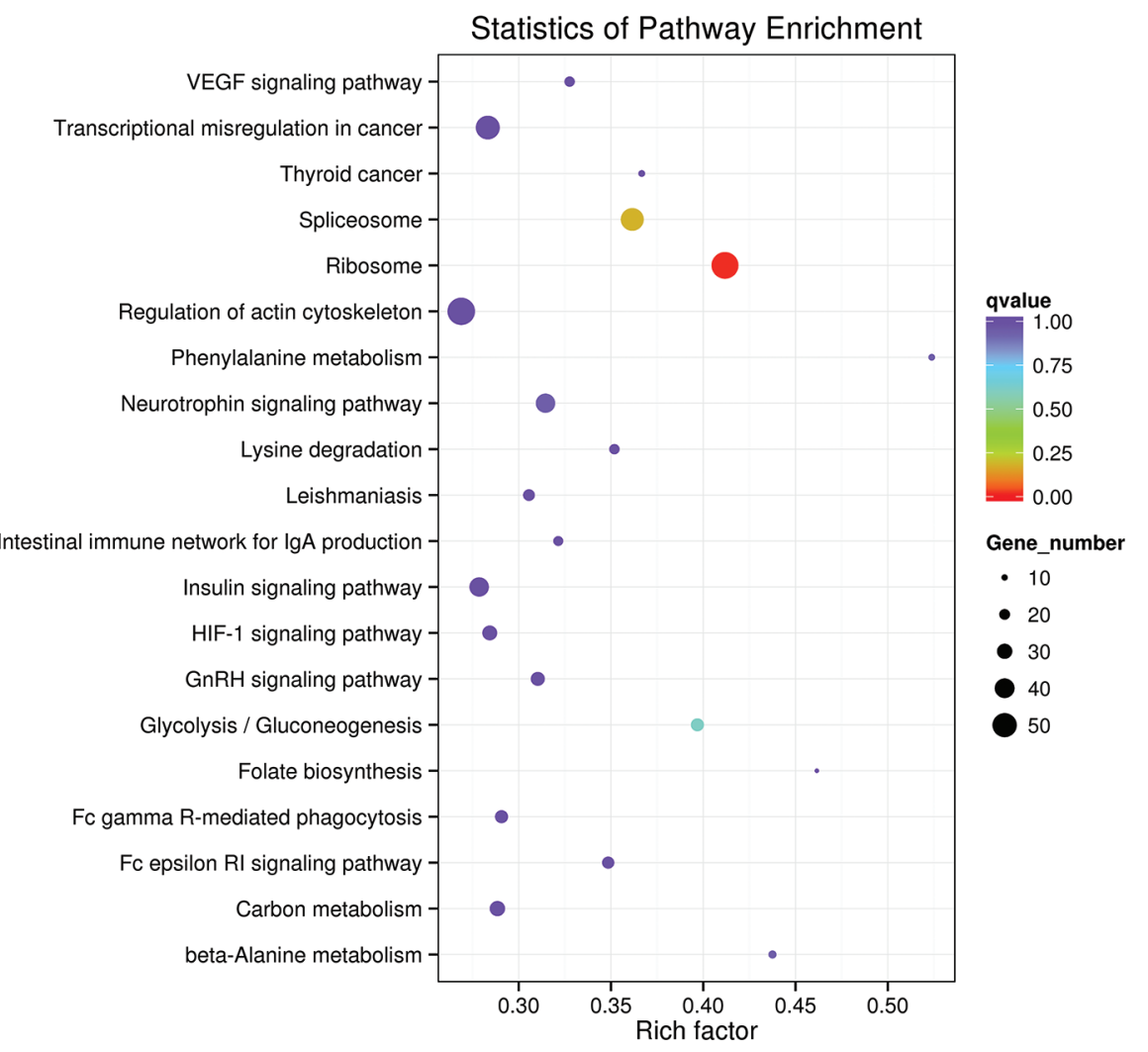

Figure 4. Cluster analysis and enrichment analysis of bovine milk exosome long noncoding RNA (lncRNA). (A) Gene ontology (GO) annotation analysis. (B) Kyoto Encyclopedia of Genes and Genomes (KEGG) enrichment analysis of neighboring gene functions. BP = biological process; CC = cellular component; MF = molecular function. 
(Figure 7). Taken together, these results indicate that the digestive process did not affect the characteristic features or lncRNA components of the milk exosomes.

\section{DISCUSSION}

In the present study, we explored a comprehensive BME lncRNA expression profile via deep sequencing. We identified 3,481 lncRNA in BME. Comparison of the genomic features of lncRNA and mRNA revealed that our observations coincided with recent studies (Ren et al., 2016; Ma et al., 2017). Moreover, the PCR product sequence of 12 lncRNA in BME was basically matched (Dohm et al., 2008). To the best of our knowledge, this is the first work to report lncRNA in exosomes from bovine milk, although previous studies have confirmed the presence of mRNA and miRNA in BME (Chen et al., 2010; Izumi et al., 2015). Our results provide supplemental evidence for future research into bovine milk RNA.
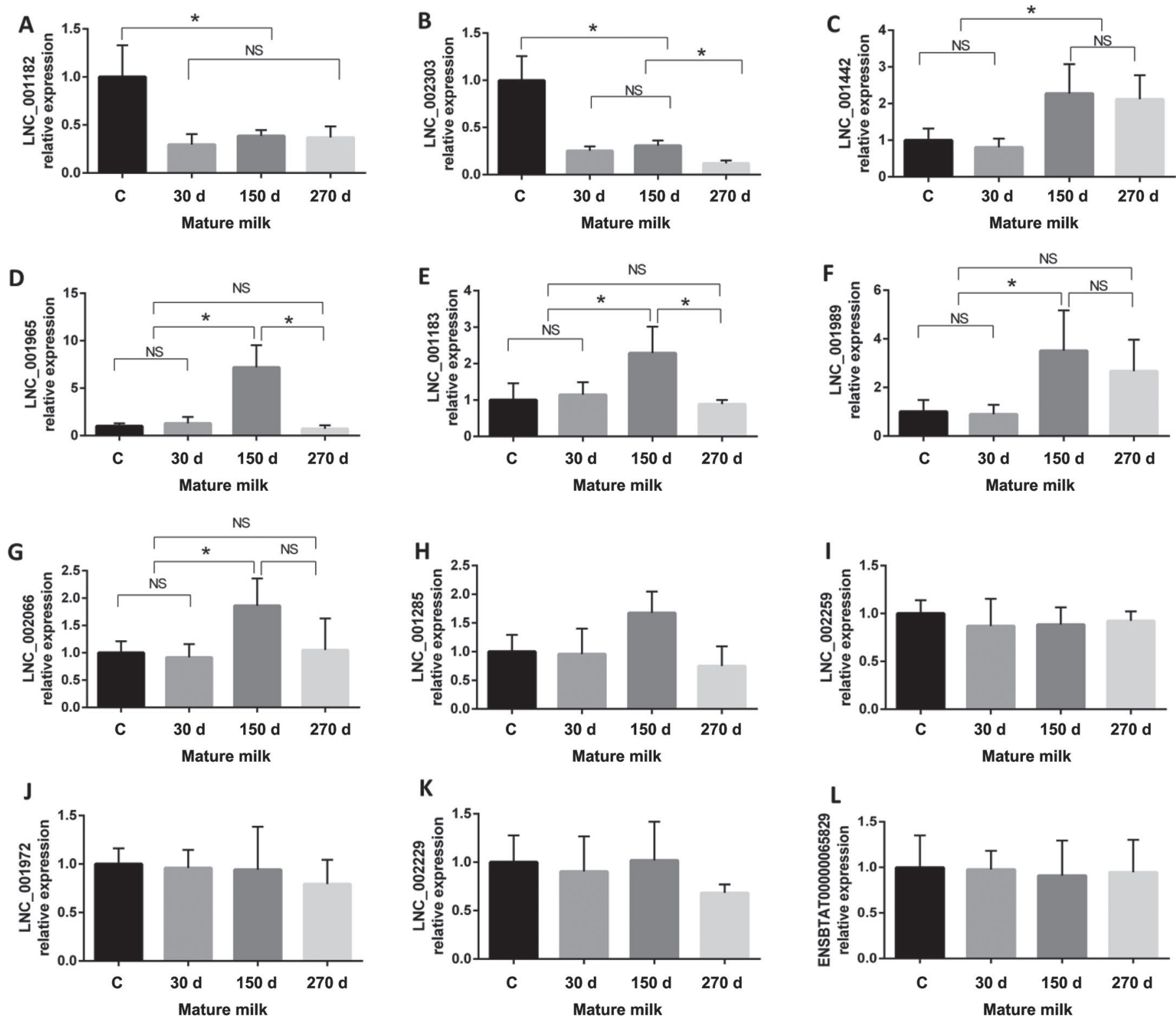

Figure 5. Quantitative real-time PCR analysis of selected long noncoding RNA (lncRNA; LNC) with normalization. To measure the expression levels of lncRNA in equal volumes and protein contents of exosomes from 4 periods of lactation milk $(\mathrm{C}=$ colostrum; 30,150, and $270 \mathrm{~d}=$ mature milk from different stages of lactation), quantitative PCR data obtained were normalized to a synthesized exogenous reference $\lambda$ polyA + RNA. The expression of indicated genes was normalized to an exogenous reference control using $2^{-\Delta \Delta \mathrm{Ct}}$ method. Values are mean \pm SEM (n $=6) .{ }^{*} P<0.05$. 
Breast milk is the optimal food for infants and will never be fully equivalent to artificial substitutes (Sobti et al., 2002). Traditionally, immunoglobulins and nonnutritional bioactive factors in milk have been considered the main regulated immunity substance. More recently, scientific interest in the modulating function of milk exosomal RNA has increased. Exosomes are of particular interest, because the cargo of sorting in exosomes is a regulated, nonrandom process, and exosomes play essential roles in cell-to-cell communication. Previous studies have indicated that RNA are selectively encapsulated into exosomes (Skog et al., 2008). We found that lncRNA encapsulated in BME were expressed at higher levels than mRNA. Functional analysis showed that BME lncRNA target genes were enriched in many biological processes that are essential for the growth and development of infants. The BME lncRNA have been predicted to be involved in antigen processing and presentation, the regulation of interferon and tumor necrosis factor production, thymus development, and the FceRI signaling pathway, which are associated with immune response (Kawakami and Galli, 2002). Emerging diverse mechanisms for lncRNA have demonstrated their effect on innate and adaptive immunity (Aune and Spurlock, 2016). Izumi et al. (2015) have suggested that cargos in BME, particularly RNA, are delivered to circulating immune cells in humans. Arntz et al. (2015) have reported that oral administration of bovine milkderived exosomes attenuate autoimmune and inflammatory diseases, possibly because BME contains many immunoregulatory RNA. It was also revealed by GO and KEGG analysis that osteoblast differentiation, embryonic cranial skeleton morphogenesis, and regulation of actin cytoskeleton were enriched. A previous study (Oliveira et al., 2016) found that BME increase osteocyte number and woven bone formation, contributing to altered osteoblast differentiation and bone matrix formation in mice, and increased osteoblast differentia-

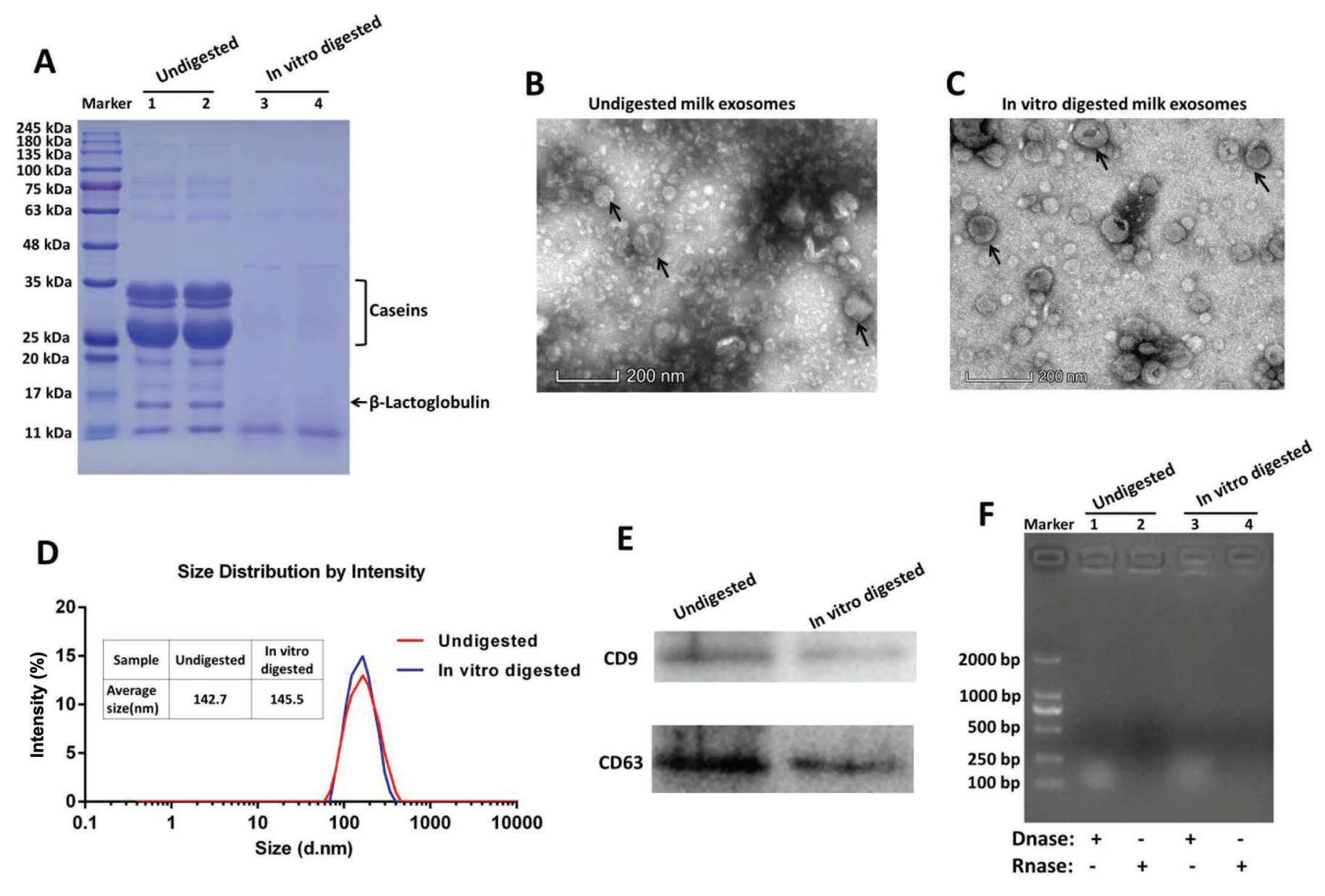

Figure 6. (A) Sodium dodecyl sulfate-PAGE (10\%) analysis; equal amounts of protein $(20 \mu \mathrm{g})$ isolated from undigested and in vitro-digested milk were loaded onto the gel and stained with $0.1 \%$ Coomassie Brilliant Blue R-250; (B) transmission electron microscopy analysis of undigested milk exosomes (indicated by arrows) and (C) in vitro-digested milk exosomes; (D) size distribution analysis of undigested and in vitro-digested milk exosomes; (E) bovine milk exosome proteins from undigested and in vitro-digested milk resolved by SDS-PAGE, and analyzed by Western blot (2 positive markers, CD9 and CD63); (F) agarose gel analysis of RNA extracted from undigested and in vitro-digested milk exosomes. 
tion in human bone marrow-derived mesenchymal stem cells. We know that BME also regulate skeletal muscle development. Mobley et al. (2017) reported that bovine whey protein contains exosomes capable of stimulating an anabolic response in skeletal muscle cells. Leiferman et al. (2018) obtained bovine milk exosome- and RNAdepleted (ERD) diets by ultrasound (ultrasonication leads to $>98 \%$ depletion of RNA cargos in exosomes, $>20 \%$ decrease in exosome count) and found that BME and their RNA cargos have moderate effects on skeletal muscle in mice. In our study, functional analysis showed that BME lncRNA target genes were also enriched in neurodevelopment and reproduction, which included neuron projection development, response to progesterone, androgen receptor binding, the neurotrophin signaling pathway, the gonadotropin-releasing hormone signaling pathway, and the vascular endothelial growth factor signaling pathway. More recently, Zempleni et al. (2019) reviewed milk-derived exosomes, mentioning much of their unpublished data. The ERD and exosome- and RNA-sufficient (ERS) diets are used to assess various phenotypes from dietary depletion of BME in mice. Mice fed an ERD diet exhibited a loss of spatial learning and memory, and a loss in fecundity compared with ERS controls. Hepatic levels of purine metabolites were substantially higher in mice fed the ERD diet than in ERS controls. The litter size produced by ERS breeders was twice that of the litter size of ERD breeders (Zempleni et al., 2019). Based on our findings and those of other teams, we suggest that the abundant lncRNA in BME may be absorbed by infants and play an important role in their growth and development. Milk not only provides nutrition, but also can serve as important information transfer for infants, and lncRNA are potential regulatory molecules in bovine milk.

In this study, the profile of lncRNA in BME from different lactation periods showed diverse expression. We found that expression of LNC_001182 and LNC_002303 were higher in colostrum than in mature milk. Earlier studies (Izumi et al., 2012; Sun et al., 2013b) provided strong evidence that related to immune development were significantly higher in colostrum than in mature milk. Our results show that LNC_001182 and LNC_002303 could be involved in the regulation organ or immune system development in newborn calves, but further research is needed to describe the detailed mechanisms. We found that 4 lncRNA (LNC_001965, LNC_001183, LNC_001989, and LNC_002066) had higher expression in mid-lactation milk $(150 \mathrm{~d})$ than in colostrum and early-lactation milk $(30 \mathrm{~d})$. These

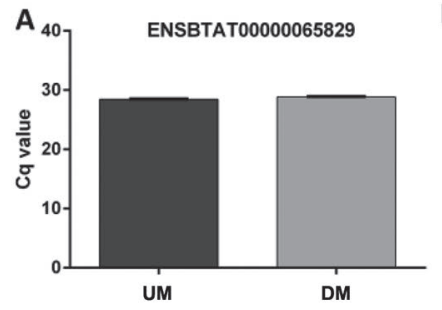

B
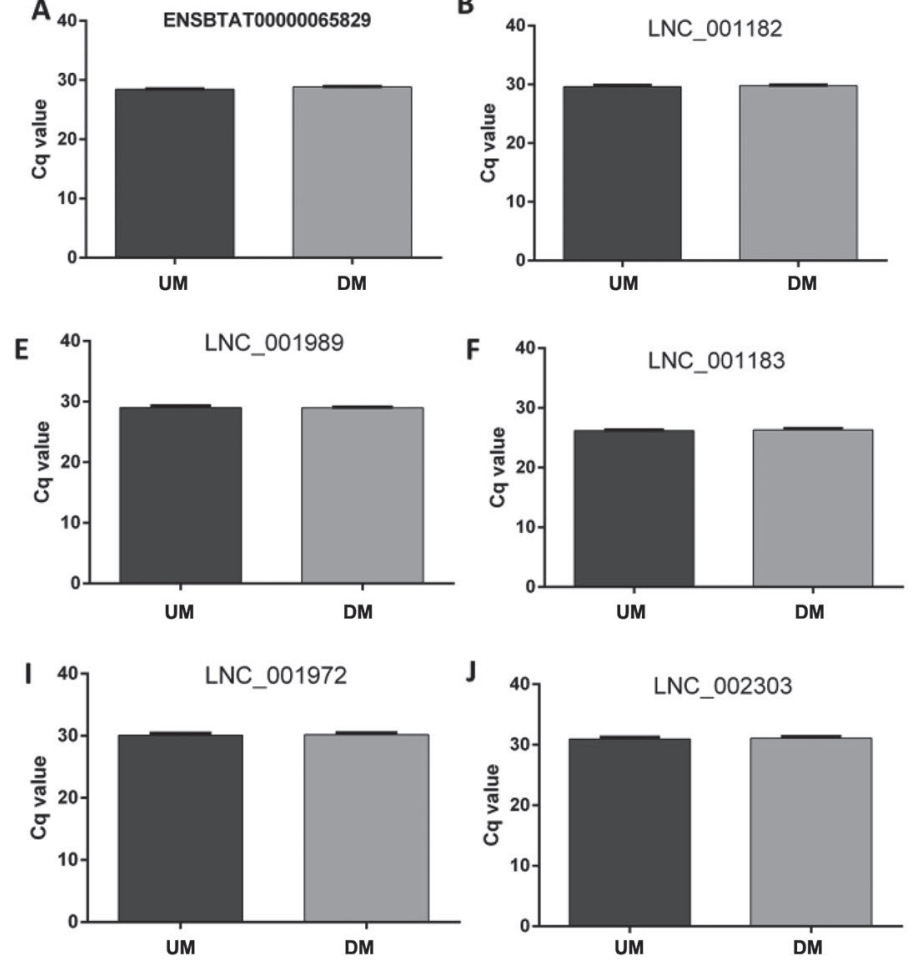

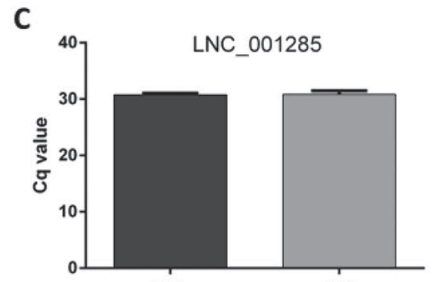

UM

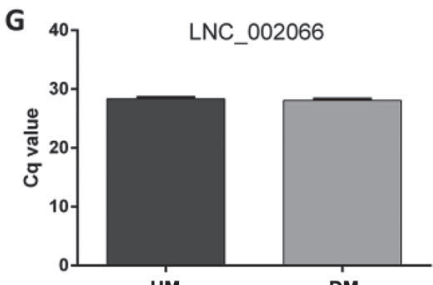

uM

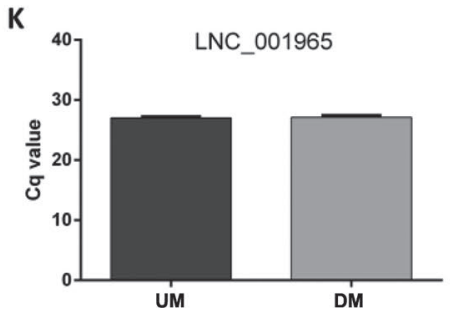

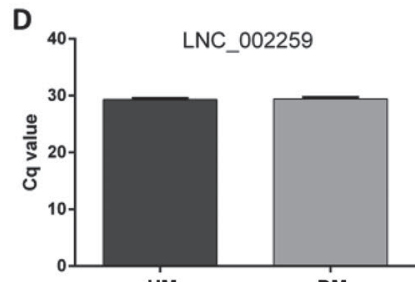

UM
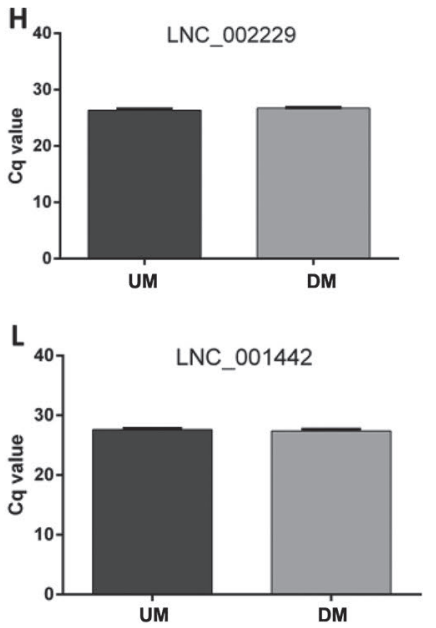

Figure 7. Analysis of abundant long noncoding RNA (lncRNA; LNC) present in undigested (UM) and in vitro-digested (DM) milk exosomes. Equal amounts of the exosomal RNA (500 ng) from undigested and in vitro-digested milk were used to synthesize cDNA. Real-time PCR of abundant lncRNA was done using the SYBR Green kit. The y-axis indicates cycle quantification $\left(\mathrm{C}_{\mathrm{q}}\right)$ values obtained after real-time $\mathrm{PCR}$. Values are mean \pm SEM $(\mathrm{n}=3)$. 
findings suggest that the levels of these lncRNA may change to accommodate infants' development requirements and the regulation of lactation (Yang et al., 2018). We also identified 5 lncRNA (LNC_001285, LNC_002259, LNC_001972, LNC_002229 and ENSBTAT00000065829) that were present at stable levels in milk from all lactation periods. As Chen et al. (2010) have reported, stable RNA expression levels can serve as an internal "standard" or "biomarker" for quality control of milk, but more research is needed to validate these findings.

Studies have assessed the stability of milk exosomes and whether their contents can survive various digestive conditions, such as low $\mathrm{pH}$, different temperatures, and digestion in vitro (Izumi et al., 2012; Rani et al., 2017). In the present study, we used a validated in vitro digestion model (Kopf-Bolanz et al., 2012) and proved that milk exosomes and their lncRNA were stable and could resist digestive processes. According to the absence of the major caseins and $\beta$-lactoglobulin in the digested samples, we confirmed that the in vitrodigestion process for bovine milk was efficient, and that results were consistent with human digestive processes for macronutrient decomposition (Kopf-Bolanz et al., 2012). Excitingly, exosomal morphology and size showed no significant difference between undigested and in vitro-digested milk. The positive surface markers for milk exosomes, CD9 and CD63, were still present after digestion in vitro. These results confirmed that BME remained intact during the digestion process. More importantly, RNA extracted from in vitro-digested milk exosomes remained undigested (Figure 6F). Real-time $\mathrm{PCR}$ revealed that in vitro digestion did not change the levels of BME lncRNA. Thus we concluded that exosomal lncRNA in bovine milk were stable after in vitro digestive processes. Previous reports have demonstrated that milk exosomal miRNA were stable after undergoing RNase treatment, low $\mathrm{pH}$ treatment, and in vitro digestion in bovines (Izumi et al., 2012; Rani et al., 2017) and humans (Liao et al., 2017). The reason that milk exosomes and encapsulated lncRNA survive the harsh digestive processes is the protective shielding effect of the exosomal lipid-bilayer membrane, along with its embedded proteins (Théry et al., 2002; Rani et al., 2017). Survival of milk exosomal lncRNA forms a basis for their further biological activity in their recipients.

\section{CONCLUSIONS}

The present study is the first to explore BME lncRNA profiles by high-throughput sequencing. We have demonstrated that bovine milk contained lncRNA, and that most of them participated in immunity, develop- ment, and reproduction. Bovine milk exosomal lncRNA exhibited various expression patterns during different periods of lactation, representing special mechanisms for adapting to infants' development needs. We also found that milk exosomal lncRNA were stable in the harsh environment of the human digestive system in vitro. These results contribute to an increased understanding of the roles of lncRNA in BME, and build a foundation for future studies to evaluate the role of milk lncRNA in infants.

\section{ACKNOWLEDGMENTS}

This work was supported by grants from the National Key Research and Development Program of China (2016YFD0500503, 2016YFD0501205), the Natural Science Foundation of China program (31802156, 31472163, and 31872435), and the Key Project of Guangdong Provincial Nature Science Foundation (2018B030311015, 2016A030313413).

\section{REFERENCES}

Admyre, C., S. M. Johansson, K. R. Qazi, J.-J. Filen, R. Lahesmaa, M. Norman, E. P. A. Neve, A. Scheynius, and S. Gabrielsson. 2007. Exosomes with immune modulatory features are present in human breast milk. J. Immunol. 179:1969-1978.

Arntz, O. J., B. C. H. Pieters, M. C. Oliveira, M. G. A. Broeren, M. B. Bennink, M. de Vries, P. L. E. M. van Lent, M. I. Koenders, W. B. van den Berg, P. M. van der Kraan, and F. A. J. van de Loo. 2015. Oral administration of bovine milk derived extracellular vesicles attenuates arthritis in two mouse models. Mol. Nutr. Food Res. 59:1701-1712.

Aune, T. M., and C. F. Spurlock III.. 2016. Long non-coding RNAs in innate and adaptive immunity. Virus Res. 212:146-160.

Bateman, A., L. Coin, R. Durbin, R. D. Finn, V. Hollich, S. GriffithsJones, A. Khanna, M. Marshall, S. Moxon, E. L. L. Sonnhammer, D. J. Studholme, C. Yeats, and S. R. Eddy. 2004. The Pfam protein families database. Nucleic Acids Res. 32:D138-D141.

Batista, P. J., and H. Y. Chang. 2013. Long noncoding RNAs: Cellular address codes in development and disease. Cell 152:1298-1307.

Chen, T., Q.-Y. Xi, R.-S. Ye, X. Cheng, Q.-E. Qi, S.-B. Wang, G. Shu, L.-N. Wang, X.-T. Zhu, Q.-Y. Jiang, and Y.-L. Zhang. 2014. Exploration of microRNAs in porcine milk exosomes. BMC Genomics 15:100.

Chen, X., C. Gao, H. Li, L. Huang, Q. Sun, Y. Dong, C. Tian, S. Gao, H. Dong, D. Guan, X. Hu, S. Zhao, L. Li, L. Zhu, Q. Tan, J. Zhang, K. Zen, and C.-Y. Zhang. 2010. Identification and characterization of microRNAs in raw milk during different periods of lactation, commercial fluid, and powdered milk products. Cell Res. 20:1128-1137.

Dieterich, C. M., J. P. Felice, E. O'Sullivan, and K. M. Rasmussen. 2013. Breastfeeding and health outcomes for the mother-infant dyad. Pediatr. Clin. North Am. 60:31-48.

Dohm, J. C., C. Lottaz, T. Borodina, and H. Himmelbauer. 2008. Substantial biases in ultra-short read data sets from high-throughput DNA sequencing. Nucleic Acids Res. 36:e105.

Gilsbach, R., M. Kouta, H. Bonisch, and M. Bruss. 2006. Comparison of in vitro and in vivo reference genes for internal standardization of real-time PCR data. Biotechniques 40:173-177.

Hauck, F. R., J. M. D. Thompson, K. O. Tanabe, R. Y. Moon, and M. M. Vennemann. 2011. Breastfeeding and reduced risk of sudden infant death syndrome: A meta-analysis. Pediatrics 128:103-110. 
Hock, A., H. Miyake, B. Li, C. Lee, L. Ermini, Y. Koike, Y. Chen, P. Maattanen, A. Zani, and A. Pierro. 2017. Breast milk-derived exosomes promote intestinal epithelial cell growth. J. Pediatr. Surg. 52:755-759.

Izumi, H., N. Kosaka, T. Shimizu, K. Sekine, T. Ochiya, and M. Takase. 2012. Bovine milk contains microRNA and messenger RNA that are stable under degradative conditions. J. Dairy Sci. 95:4831-4841.

Izumi, H., M. Tsuda, Y. Sato, N. Kosaka, T. Ochiya, H. Iwamoto, K. Namba, and Y. Takeda. 2015. Bovine milk exosomes contain microRNA and mRNA and are taken up by human macrophages. J. Dairy Sci. 98:2920-2933.

Karlsson, O., R. S. Rodosthenous, C. Jara, K. J. Brennan, R. O. Wright, A. A. Baccarelli, and R. J. Wright. 2016. Detection of long non-coding RNAs in human breastmilk extracellular vesicles: Implications for early child development. Epigenetics 11:721-729.

Kawakami, T., and S. J. Galli. 2002. Regulation of mast-cell and basophil function and survival by IgE. Nat. Rev. Immunol. 2:773-786.

Kong, L., Y. Zhang, Z.-Q. Ye, X.-Q. Liu, S.-Q. Zhao, L. Wei, and G. Gao. 2007. CPC: Assess the protein-coding potential of transcripts using sequence features and support vector machine. Nucleic Acids Res. 35:W345-W349.

Kopf-Bolanz, K. A., F. Schwander, M. Gijs, G. Vergeres, R. Portmann, and L. Egger. 2012. Validation of an in vitro digestive system for studying macronutrient decomposition in humans. J. Nutr. 142:245-250

Langmead, B., and S. L. Salzberg. 2012. Fast gapped-read alignment with Bowtie 2. Nat. Methods 9:357-359.

Leiferman, A., J. Shu, R. Grove, J. Cui, J. Adamec, and J. Zempleni. 2018. A diet defined by its content of bovine milk exosomes and their RNA cargos has moderate effects on gene expression, amino acid profiles and grip strength in skeletal muscle in C57BL/6 mice. J. Nutr. Biochem. 59:123-128.

Liao, Y., X. Du, J. Li, and B. Lonnerdal. 2017. Human milk exosomes and their microRNAs survive digestion in vitro and are taken up by human intestinal cells. Mol. Nutr. Food Res. 61.

Ma, Q., L. Li, Y. Tang, Q. Fu, S. Liu, S. Hu, J. Qiao, C. Chen, and W. Ni. 2017. Analyses of long non-coding RNAs and mRNA profiling through RNA sequencing of MDBK cells at different stages of bovine viral diarrhea virus infection. Res. Vet. Sci. 115:508-516.

Manca, S., B. Upadhyaya, E. Mutai, A. T. Desaulniers, R. A. Cederberg, B. R. White, and J. Zempleni. 2018. Milk exosomes are bioavailable and distinct microRNA cargos have unique tissue distribution patterns. Sci. Rep. 8:11321.

Mao, X., T. Cai, J. G. Olyarchuk, and L. Wei. 2005. Automated genome annotation and pathway identification using the KEGG Orthology (KO) as a controlled vocabulary. Bioinformatics 21:37873793.

Mobley, C. B., P. W. Mumford, J. J. McCarthy, M. E. Miller, K. C. Young, J. S. Martin, D. T. Beck, C. M. Lockwood, and M. D. Roberts. 2017. Whey protein-derived exosomes increase protein synthesis and hypertrophy in $\mathrm{C} 2 \mathrm{C} 12$ myotubes. J. Dairy Sci. 100:48-64.

Nabet, B. Y., Y. Qiu, J. E. Shabason, T. J. Wu, T. Yoon, B. C. Kim, J. L. Benci, A. M. DeMichele, J. Tchou, J. Marcotrigiano, and A. J. Minn. 2017. Exosome RNA unshielding couples stromal activation to pattern recognition receptor signaling in cancer. Cell 170:352-366.e13.

Oliveira, M. C., O. J. Arntz, E. N. B. Davidson, P. L. E. M. van Lent, M. I. Koenders, P. M. van der Kraan, W. B. van den Berg, A. V. M. Ferreira, and F. A. J. van de Loo. 2016. Milk extracellular vesicles accelerate osteoblastogenesis but impair bone matrix formation. J. Nutr. Biochem. 30:74-84.

Ørom, U. A., T. Derrien, M. Beringer, K. Gumireddy, A. Gardini, G. Bussotti, F. Lai, M. Zytnicki, C. Notredame, Q. Huang, R. Guigo, and R. Shiekhattar. 2010. Long Noncoding RNAs with Enhancerlike Function in Human Cells. Cell 143:46-58.

Pertea, M., D. Kim, G. M. Pertea, J. T. Leek, and S. L. Salzberg. 2016. Transcript-level expression analysis of RNA-seq experiments with HISAT, StringTie and Ballgown. Nat. Protoc. 11:1650-1667.
Rani, P., M. Vashisht, N. Golla, S. Shandilya, S. K. Onteru, and D. Singh. 2017. Milk miRNAs encapsulated in exosomes are stable to human digestion and permeable to intestinal barrier in vitro. J. Funct. Foods 34:431-439.

Ren, H., G. Wang, L. Chen, J. Jiang, L. Liu, N. Li, J. Zhao, X. Sun, and P. Zhou. 2016. Genome-wide analysis of long non-coding RNAs at early stage of skin pigmentation in goats (Capra hircus). BMC Genomics 17:67.

Savino, F., and S. A. Liguori. 2008. Update on breast milk hormones: Leptin, ghrelin and adiponectin. Clin. Nutr. 27:42-47.

Skog, J., T. Wuerdinger, S. van Rijn, D. H. Meijer, L. Gainche, M. Sena-Esteves, W. T. Curry Jr., B. S. Carter, A. M. Krichevsky, and X. O. Breakefield. 2008. Glioblastoma microvesicles transport RNA and proteins that promote tumour growth and provide diagnostic biomarkers. Nat. Cell Biol. 10:1470-1476.

Sobti, J., G. P. Mathur, A. Gupta, and World Health Organization. 2002. WHO's proposed global strategy for infant and young child feeding: A viewpoint. J. Indian Med. Assoc. 100:502-504.

Sun, L., H. Luo, D. Bu, G. Zhao, K. Yu, C. Zhang, Y. Liu, R. Chen, and Y. Zhao. 2013a. Utilizing sequence intrinsic composition to classify protein-coding and long non-coding transcripts. Nucleic Acids Res. 41.e166

Sun, Q., X. Chen, J. Yu, K. Zen, C.-Y. Zhang, and L. Li. 2013b. Immune modulatory function of abundant immune-related microRNAs in microvesicles from bovine colostrum. Protein Cell 4:197-210.

Théry, C., L. Zitvogel, and S. Amigorena. 2002. Exosomes: Composition, biogenesis and function. Nat. Rev. Immunol. 2:569-579.

Title, A. C., R. Denzler, and M. Stoffel. 2015. Uptake and function studies of maternal milk-derived microRNAs. J. Biol. Chem. 290:23680-23691.

Tomé-Carneiro, J., N. Fernandez-Alonso, C. Tomas-Zapico, F. Visioli, E. Iglesias-Gutierrez, and A. Davalos. 2018. Breast milk microRNAs harsh journey towards potential effects in infant development and maturation. Lipid encapsulation can help. Pharmacol. Res. $132: 21-32$.

Trapnell, C., B. A. Williams, G. Pertea, A. Mortazavi, G. Kwan, M. J. van Baren, S. L. Salzberg, B. J. Wold, and L. Pachter. 2010. Transcript assembly and quantification by RNA-Seq reveals unannotated transcripts and isoform switching during cell differentiation. Nat. Biotechnol. 28:511-515.

Vlassov, A. V., S. Magdaleno, R. Setterquist, and R. Conrad. 2012. Exosomes: Current knowledge of their composition, biological functions, and diagnostic and therapeutic potentials. Biochim. Biophys. Acta 1820:940-948.

Wolf, T., S. R. Baier, and J. Zempleni. 2015. The intestinal transport of bovine milk exosomes is mediated by endocytosis in human colon carcinoma Caco-2 cells and rat small intestinal IEC-6 Cells. J. Nutr. 145:2201-2206.

Yang, B., B. Jiao, W. Ge, X. Zhang, S. Wang, H. Zhao, and X. Wang. 2018. Transcriptome sequencing to detect the potential role of long non-coding RNAs in bovine mammary gland during the dry and lactation period. BMC Genomics 19:605.

Ying, W., M. Riopel, G. Bandyopadhyay, Y. Dong, A. Birmingham, J. B. Seo, J. M. Ofrecio, J. Wollam, A. Hernandez-Carretero, W. Fu, P. Li, and J. M. Olefsky. 2017. Adipose tissue macrophage-derived exosomal miRNAs can modulate in vivo and in vitro insulin sensitivity. Cell 171:372-384.e12.

Young, M. D., M. J. Wakefield, G. K. Smyth, and A. Oshlack. 2010. Gene ontology analysis for RNA-seq: Accounting for selection bias. Genome Biol. 11:R14 (J).

Zempleni, J., S. Sukreet, F. Zhou, D. Wu, and E. Mutai. 2019. Milkderived exosomes and metabolic regulation. Annu. Rev. Anim. Biosci. 7:245-262

Zheng, R., M. Du, X. Wang, W. Xu, J. Liang, W. Wang, Q. Lv, C. Qin, H. Chu, M. Wang, L. Yuan, J. Qian, and Z. Zhang. 2018. Exosome-transmitted long non-coding RNA PTENP1 suppresses bladder cancer progression. Mol. Cancer 17:143.

Zhou, Q., M. Li, X. Wang, Q. Li, T. Wang, Q. Zhu, X. Zhou, X. Wang, X. Gao, and X. Li. 2012. Immune-related MicroRNAs are abundant in breast milk exosomes. Int. J. Biol. Sci. 8:118-123. 